\section{Antigens in Human Sarcomas and Melanomas}

That viruses may play some part in causing human cancers is suspected but not yet proved. ${ }^{1}$ Laboratory studies show that tumours induced by the same virus in different hosts may share common antigens despite genetic differences between the hosts ${ }^{2}$ and that the reaction of the hosts to the antigens in their tumours may entail the production of circulating antibodies. One way of looking for viruses that cause cancer in man, therefore, is to seek common antibodies against tumours in patients with particular forms of cancer. Two such studies have recently been reported by $\mathrm{D}$. L. Morton and A. Malmgren and their associates in Bethesda. ${ }^{3-6}$

Antibodies against melanoma were found ${ }^{3}$ in all of six patients whose sera were tested against their own malignant melanomas by an indirect immunofluorescent technique. ${ }^{4}$ Positive results were also obtained with 84 out of 138 (61\%) sera from patients with melanomas tested against cells from other melanoma cases. But 25 out of 125 (20\%) of tests of normal sera were also positive against melanoma cells. Other studies confirmed the specificity of the reaction in the case of four out of six sera from melanoma patients and homologous melanoma cells.

The report from Dr. M. G. Lewis and colleagues at page 547 of the B.M.f. this week constitutes a partial confirmation and extension of Morton and Malmgren's studies in respect of melanomas. In particular they make the new observation that the chance of finding autoantibodies was highest in patients in whom the disease is not widely disseminated. The fact that the disappearance of antibodies in three patients coincided with the progression of the disease from a stage of limited extension to one of wider dissemination is difficult to interpret. Despite the attraction of the theory that the increase in malignant behaviour followed the loss of tumourspecific antigens, it remains unproved. The observation that the inoculation of irradiated autologous melanoma cells " after extensive removal of disseminated tumour" enabled cytotoxic serum autoantibody to be detected in two cases in which none could previously be found may indicate that tumour-specific antigens are in fact not lost but merely rendered undetectable when tumours become widely disseminated.

At the end of 1968 Morton and Malmgren ${ }^{4}$ reported an extension of their studies to human osteogenic sarcomas. Positive results were obtained in tests of sera from patients

1 Fairley, G. H., British Medical fournal, 1969, 2, 467.

- Old, L. J., and Boyse, E. A., Federation Proceedings, 1965, 24, 1009.

- Morton, D. L., Malmgren, R. A., Holmes, E. C., and Ketcham, A. S., Surgery, 1968, 64, 233.

- Morton, D. L., and Malmgren, R. A., Science, 1968, 162, 1279.

- Morton, D. L., Malmgren, R. A., Hall, W. T., and Schidlovsky, G., Surgery, 1969, in press.

- Malmgren, R. A., in Viruses Inducing Cancer, 1966, ed. W. J. Burdette. Salt Lake City, University of Utah Press.

' Moseley, J. E., and Bass, M. H., Radiology, 1956, 66, 41.

- Roberts, C. W., and Roberts, C. P., Fournal of the American Medical Association, 1935, 105, 181. - Robbins, R., Fournal of the American Medical Association, 1967, 202,
1055.

10 Pohle, E. A., Stovall, W. D., and Boyer, H. N., Radiology, 1936, 27, 545.

1 Harmon, T. P., and Morton, K. S., Fournal of Bone and Foint Surgery, 1966, 48B, 493.

12 Schajowicz, F., and Bessone, J. E., fournal of Bone and foint Surgery, 1967, 49A, 129. 15 Finkel, M. P., Biskis, B. O., and Jinkins, P. B., Science, 1966, 151,
698 .

14 Finkel, M. P., Biskis, B. O., and Farrell, C., Proceedings of the National Academy of Sciences, 1968, 60, 1223. with osteosarcoma against autologous or homologous osteosarcoma sera and also in 45 out of 52 tests against sera from patients' relatives or close associates. As in the melanoma survey, blocking and absorption studies confirmed the specificity of positive reactions. More recent studies ${ }^{5}$ have shown cross-reactivity with sarcomas of other types, including liposarcomas, fibrosarcomas, and chondrosarcomas. Reactions were also seen with two out of four melanomas tested.

A number of clinical observations suggest that osteogenic sarcoma may have a viral aetiology. It has, for instance, a predilection for young people, it may occur simultaneously at multiple sites in the same patient, ${ }^{7}$ and it has been reported as developing simultaneously in as many as three members of a single family. ${ }^{8}$ Other reports of the familial incidence of sarcomas $^{9-12}$ seem to suggest a genetic origin but are not inconsistent with the vertical transmission of a virus-that is, from parent to child before or very shortly after birth. The patients studied by Morton and Malmgren ${ }^{4}$ differed from each other in sex and blood group.

If a virus is responsible for the presence of specific antigens in patients with osteogenic sarcomas, the occurrence of specific antibodies in normal sera shows that the disease is not an invariable consequence of infection. Indeed, the virus may be no more than a common passenger to the carriage of which patients with sarcoma are exceptionally susceptible. To fulfil Koch's postulates in relation to the causation of human cancer by a virus is notoriously difficult. On the other hand, the demonstration of the passage of an infectious agent from a culture derived from a sarcoma to a culture of normal human embryo cells $s^{5}$ may be more significant.

One must expect that it will take time and painstaking work before the true explanation of the observations reported by Morton and his colleagues is known. In the meantime the discovery that osteogenic sarcoma can be induced by viral agents in mice $^{13}$ and hamsters ${ }^{14}$ makes the proposition that human sarcomas may also have a viral origin basically tenable.

\section{Tennis Leg}

Sometimes a tennis player has a sharp pain in the calf so sudden and unexpected that he turns to see who hit him, and occasionally it is so severe that he collapses and has to be helped from the court. A similar pain may occur in squash, cricket, ski-ing, athletics, and other sports. Clinically the cause is a tear at the musculo-tendinous junction of the medial belly of the gastrocnemius, and this has been confirmed by $\mathrm{O}$. Arner and A. Lindholm ${ }^{1}$ from operating on five patients. On clinical examination there is local tenderness, and a gap in the muscle is usually palpable in the first 24 hours. After that swelling may be considerable and it is often accompanied by obvious bruising. The injury occurs mostly in older players, and A. I. Froimson ${ }^{2}$ reports that there may be a prodromal ache in the calf for a day or two beforehand. Arner and Lindholm analysed the mechanism of injury in 20 patients and showed that it follows a stroke played with the back foot supinated and the knee extended.

1 Arner, O., and Lindholm, A., Acta Chirurgica Scandinavica, 1958, 116, 73.

- Froimson, A. I., fournal of the American Medical Association, 1969, 209, 415.

s Ljungqvist, R., Acta Orthopaedica Scandinavica, Supplement No. 113, 1968.

- Hood, W. P., Lancet, 1884, 2, 728. 